\title{
Afferents to the Optic Tectum of the Leopard Frog: An HRP Study
}

\author{
WALT WILCZYNSKI AND R. GLENN NORTHCUTT \\ Neurosciences Program, University of Michigan, Ann Arbor, Michigan 48109 \\ and Ditision of Biological Sciences, University of Michigan. Ann Arbor, \\ Michigan 48109
}

\begin{abstract}
Following unilateral HRP injections in the optic tectum of Rana pipiens, HRP-positive cells were seen in three pretectal nuclei: bilaterally in the dorsal posterior nucleus; in the dorsal half of the ipsilateral posterior nucleus; and ipsilaterally in the large-celled pretectal nucleus. HRP-positive cells were also seen ipsilaterally in the anterodorsal, posterodorsal and posteroventral tegmental fields. the nucleus isthmi, and the dorsal gray columns of the cervical spinal cord; bilaterally in the suprapeduncular nucleus, a paramedian cell group dorsal to the interpeduncular nucleus; and in the deep layers of the contralateral tectum. In addition, evidence for a bilateral ventral preopto-tectal projection was seen in half the experimental animals. No tectal afferents from telencephalic or rostral thalamic areas were seen. Both the ascending and descending tectal efferent fibers were also filled with reaction product. The pale reaction indicative of terminating tectal efferents was seen in the dorsal pretectum, partially overlapping the lateral nucleus and uncinate neuropil; in the core of nucleus isthmi; and in the superior olive.
\end{abstract}

The optic tectum of anuran amphibians has received considerable attention as an important visuomotor area integrating several sensory modalities. At least two distinct behaviors are mediated by this structure (Ingle, '70): orientation toward and away from visual stimuli. Neither behavior is a simple on-off response. Rather, each is a sequence of behavioral subunits dependent on stimulus variables such as size, physical configuration, orientation, speed, direction, distance from the animal, the presence of stationary barriers, and the features of concurrent non-visual stimuli (Biesner and Melzack, '66; Butenandt and Grüsser, '68; Ingle, '68, '70, '71; Ewert, 70 ).

The retinal response characteristics have been thoroughly investigated and are implicated as powerful determinants of tectally mediated behavior (Lettvin et al., '59; Maturana et al., '60). Later work demonstrates that other afferents exert an equally important modulating influence on tectal cells and thus on behavior. The pretectum controls tectal unit habituation and receptive field size (Ingle, '73a) and determines whether a particular stimulus is approached or avoided (Ewert, '70).

While the intrinsic organization of the optic tectum (Lazar and Szekely, '67; Potter, '69) and retinal terminal pattern (Gaze, '58; Lazar, '71; Szekely, '71) are well described, relatively little is known regarding tectal afferents in amphibians. Trachtenberg and Ingle ('74) reported on thalamic inputs, but their interpretations are complicated by the possible interruption of fibers of passage and the inability to determine precisely the cells of origin within such complex regions as the pretectum. Other afferent sources are unknown.

The capacity of neurons to transport horseradish peroxidase in a retrograde direction suggested its use in determining sources of tectal input. Such a study should yield a more complete picture of tectal afferents and elucidate more precisely the 
locus of pretectal neurons innervating the tectum. A preliminary report of this work has appeared previously (Wilczynski, '76).

\section{MATERIALS AND METHODS}

Unilateral tectal injections were made under MS 222 (Tricaine) anesthesia on 15 adult specimens of Rana pipiens. A skin flap was made dorsally and the underlying bone removed with a dental drill. The meninges were incised, exposing the tectum. Sigma VI horseradish peroxidase was dissolved in distilled water to yield a 30$40 \%$ solution. In two frogs the tectum was scraped free of meninges and a piece of Gelfoam soaked in the HRP solution was placed on the tectum. In eleven animals multiple 100-150 $\mathrm{nl}$ injections of the HRP solution were made unilaterally through a 33 gauge needle attached to a $5 \mu \mathrm{l} \mathrm{Ham}$ ilton syringe. Two controls were injected with distilled water instead of HRP. Following these administration procedures, the wounds were packed with Gelfoam and the skin flaps sutured into place.

After survival times of two to nine days at $25^{\circ} \mathrm{C}$, the animals were anesthetized with MS 222 and perfused transcardially with a fixative composed of $1.5 \%$ formaldehyde and $1 \%$ glutaraldehyde in a phosphate buffer adjusted to $\mathrm{pH} 7.4$ at $7^{\circ} \mathrm{C}$. The brains were removed from the skull and fixed for an additional two to three hours in cold perfusate. The brains were then transferred to phosphate buffer with
$5 \%$ sucrose $\left(7^{\circ} \mathrm{C}, \mathrm{pH} 7.4\right)$ for an additional 22 hours. The tissue was then placed in Tissue-Tec II embedding compound and sectioned at $24 \mu$ in a cryostat. Every other section was thaw mounted onto chromealum slides.

The sections were preincubated in an $0.03 \%$ solution of o-dianisidine in $\mathrm{pH} 7.4$ phosphate buffer for 30 minutes. A $0.06 \%$ solution of hydrogen peroxide was then added $\left(2.5 \mathrm{ml}\right.$ per $100 \mathrm{ml}$ of the $0^{-}$ dianisidine solution) and the sections incubated for an additional 45 minutes. After this developing process the slides were rinsed in tap water and the sections counterstained with cresyl violet, dehydrated, cleared, and coverslipped.

\section{RESULTS}

The site of HRP administration was marked by superficial damage to the tectum and a clearly defined, diffuse, dark brown core that extended from the pial surface to the ependyma (fig. 1A). A pale annulus surrounded the core, and in a few cases extended across the midline into the contralateral tectum. The injections were restricted to the tectum except for one animal in which a small portion of the underlying tegmentum was injected and another animal in which some pale diffusion product appeared in the superficial rostral cerebellum and caudal poles of the telencephalon. These exceptions were used only to corroborate the results of the

Abhreviations

A, Anterior nucleus

AD, Anterodorsal tegmental field

$\mathrm{C}$, Central nucleus

D. Dorsal nucleus of $n$. VIII

DH, Dorsal horn of spinal cord

DN, Dorsal column nucleus

Ea, Ascending tectal efferent bundle

Ec, Contralateral descending tecta]

efferent bundle

$\mathrm{Ei}$. Ipsilateral descending tectal efferent bundle

FP, Entopeduncular nucleus

$G$, Lateral geniculate nucleus of Frontera

H, Hypothalamus

Hb, Habenula

IP, Interpeduncular nucleus

Ism, Nucleus isthmi
L. Lateral nucleus

n. VIII, Eighth nerve root

OC, Optic chiasm

ON, Optic nerve

$P$, Posterior nucleus

PD, Posterodorsal tegmental field

PO, Preoptic area

PV, Posteroventral tegmental field

SHb, Subhabenular nulceus

SG, Secondary gustatory nucleus

SO, Superior olive

SP, Suprapeduncular nucleus

Tel, Telencephalon

TeO, Optic tectum

$V$, Ventral thalamus

VH, Ventral horn of spinal cord 

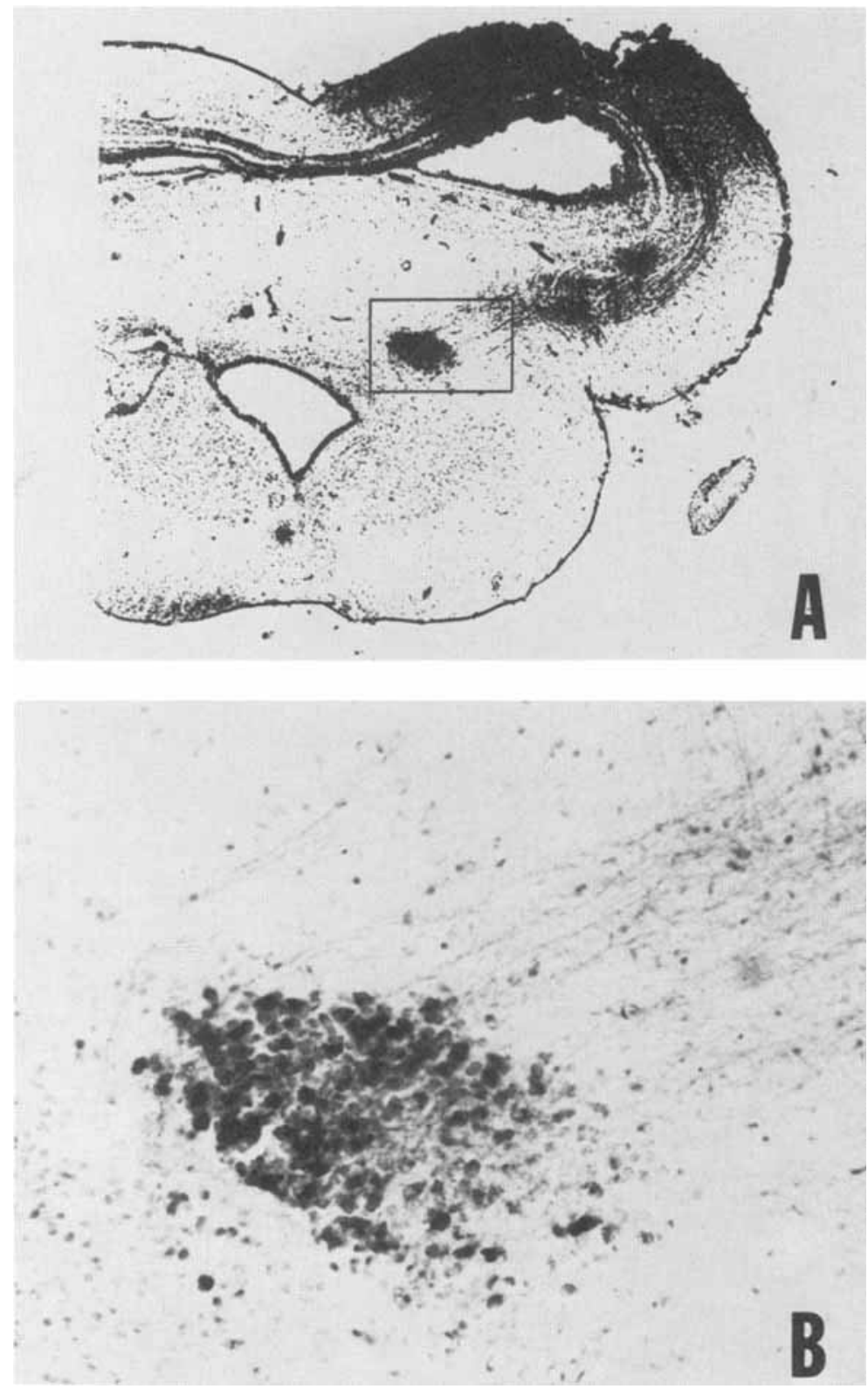

Fig. 1 A High contrast photograph of a transverse section through the tectum showing the injection site. The tissue is counterstained with cresyl violet. Superficial needle damage can be seen dorsally. A heavily stained nucleus isthmi appears ipsilaterally, and the contralateral descending tectal efferents are apparent deep to the ventral pial surface.

B Light field photomicrograph of the rostral pole of the ipsilateral nucleus isthmi in the field outlined in figure 1A. Individual cells are densely filled, and isthmotectal fibers can be seen dorsolaterally. 

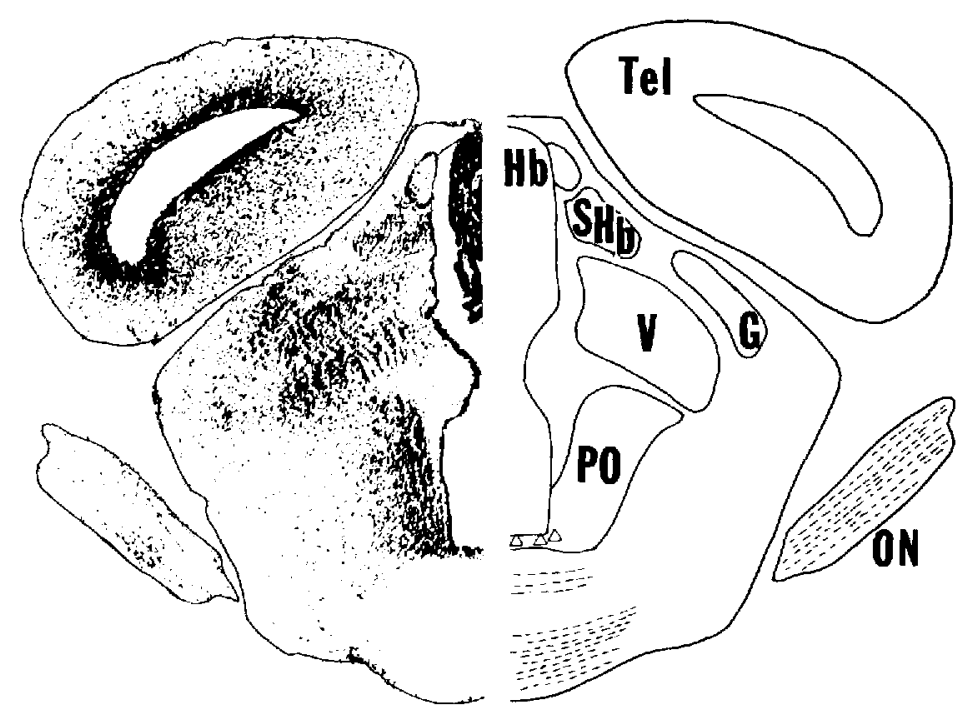

Fig. 2 Transverse section through the optic chiasm. High contrast photograph of cresyl violet stained section on left, mirror image line drawing on right. In figures 2 to 5 , broken lines indicate fibers, filled triangles represent HRP-positive cells. Open triangles indicate inconsistently scen HRP. positive cells. Left side is ipsilateral, right side contralateral to the injected tectum.

more restricted injections. In one additional animal, reaction product was observed throughout the entire brain and cervical spinal cord. This probably resulted from the inadvertent introduction of the enzyme into a major blood vessel (Broadwell and Brightman, '76). Results from this animal were disregarded. In no case did the core extend to the extreme ventrolateral aspect of the tectum.

The optimal survival time was five to six days. By nine days the cells and fibers had begun to fade. Cells in which retrograde transport of the HRP had occurred were distinguished by the presence of densely packed dark brown vesicles in the somata and proximal dendrites. Somata filled with diffuse product were frequently seen in the same areas as the vesicle filled neurons. These were probably due to incidental axonal damage at the injection site. Evidence for both retrograde and orthograde movement was seen in fiber pathways. Although no difference in appearance could be seen at the light microscopic level, the fiber bundles were identified as either afferent or efferent based on the experi- mental studies of Rubinson ('68), Scalia et al. ('68), and Lazar ('69).

The diencephalic nomenclature is based on that of Neary (75) which divides the dorsal thalamus, including the pretectum, into four groups: an anterior nucleus in the rostral pole; a central group immediately caudal; a posterior nucleus at the caudal pole; and a lateral group external to the central and posterior nuclei. The posterolateral and posteromedial pretectal nuclei of Trachtenberg and Ingle (74) correspond to the lateral and posterior in our terminology.

\section{Afferent pathways}

Fibers in the contralateral optic nerve were filled with reaction product. These fibers crossed in the optic chiasm (fig. 2), entered the optic tract, and traveled caudally (fig. 3A) to the injected tectum. We believe these fibers are retinal ganglion axons due to their large numbers and position in the optic nerve and tract.

In the pretectum, HRP positive cells were consistently seen in three areas (fig. 3B). The heaviest concentration of the 

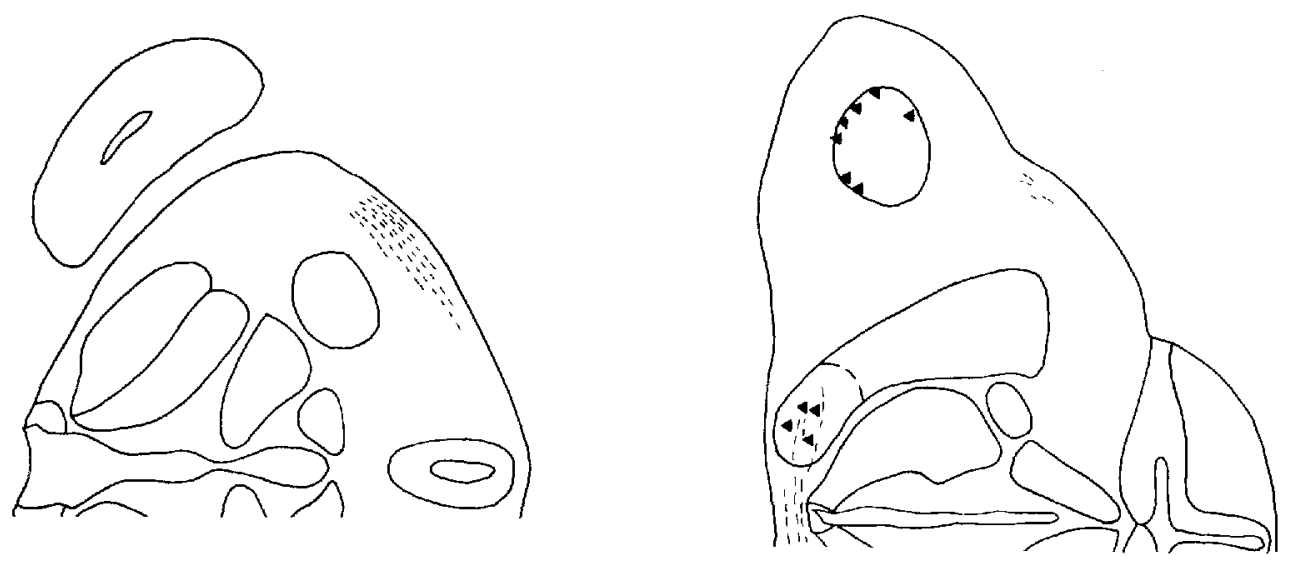

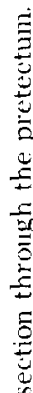
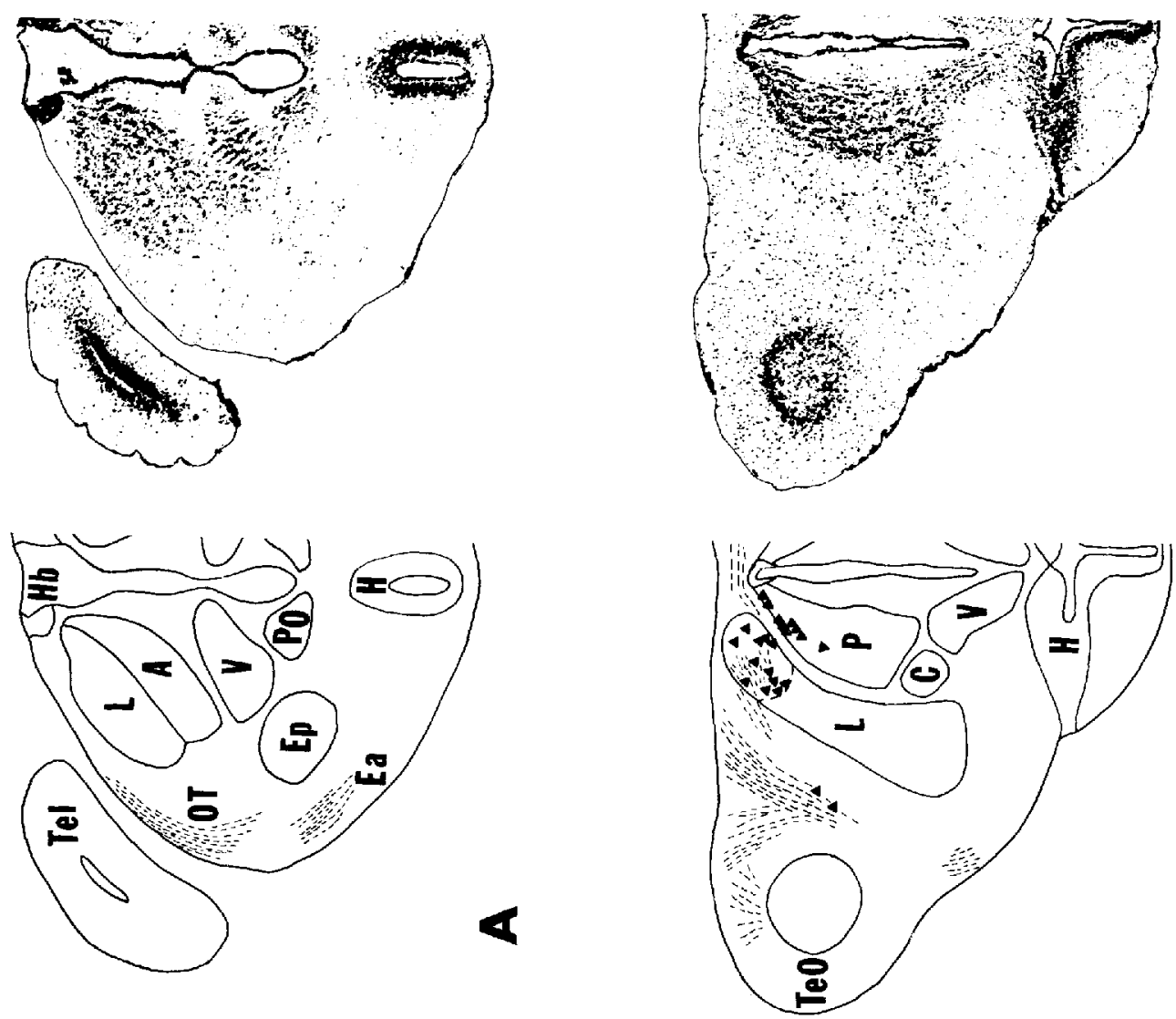

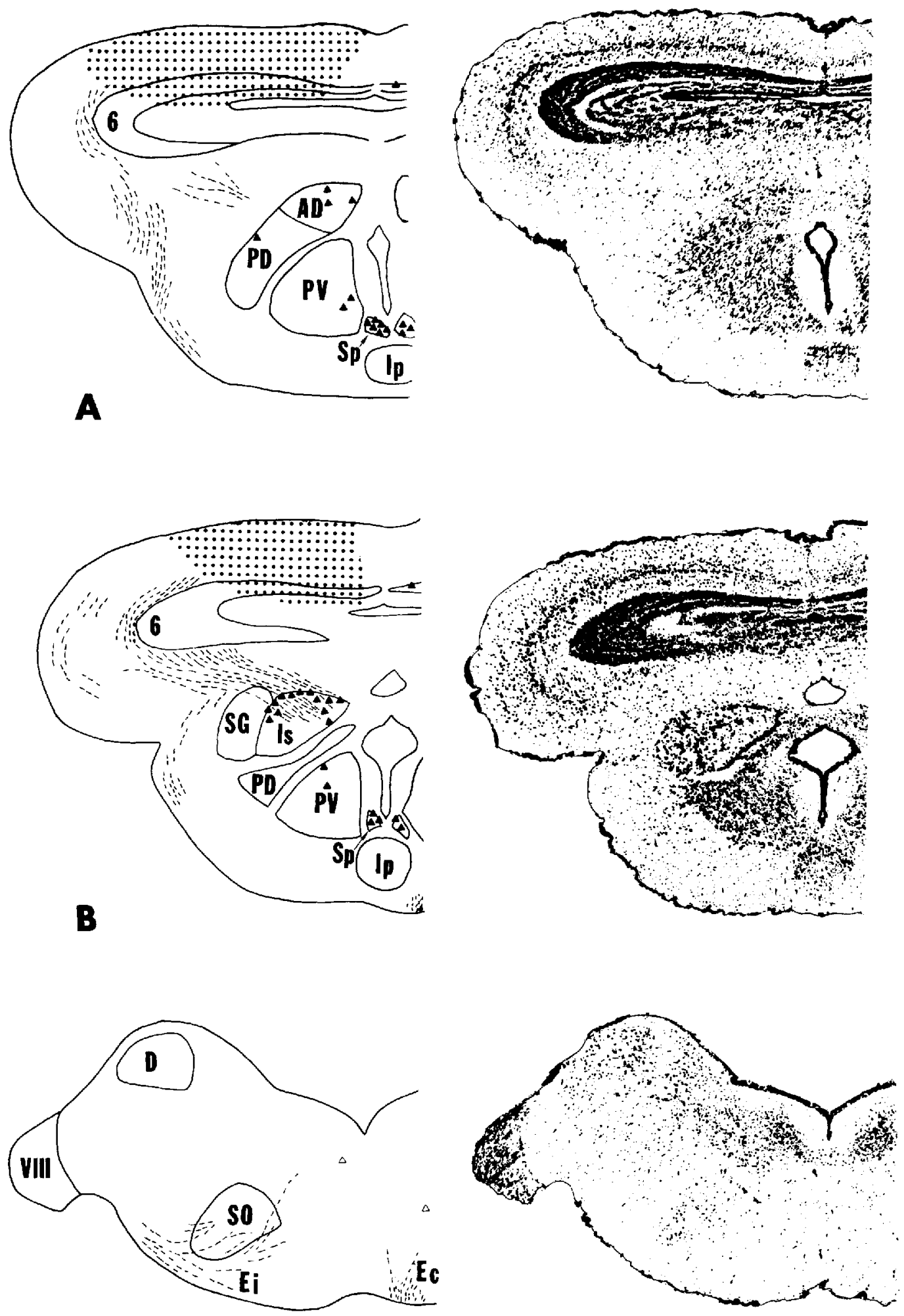

Figure 4 

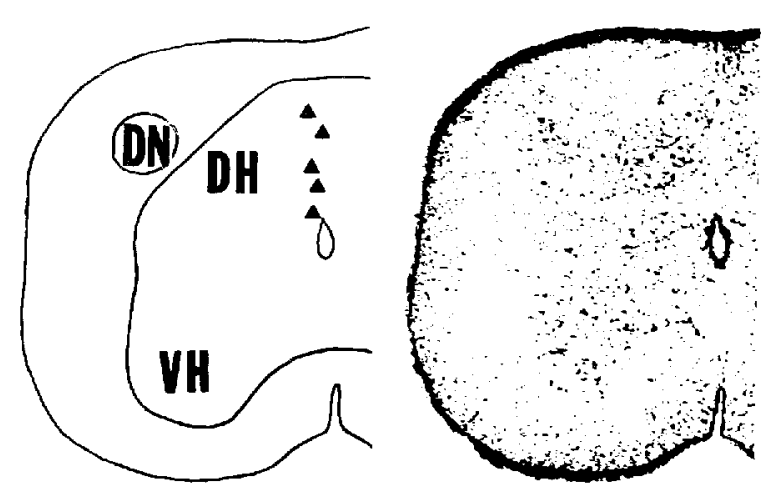

Fig. 5 Transverse section through the cervical spinal cord.

brown reaction product was in the dorsal part of the ipsilateral lateral nucleus. $\mathrm{Nu}^{-}$ merous cell bodies and fibers were seen, as well as a diffuse reaction located in a neuropil partially overlapping this lateral nucleus and the uncinate neuropil of Scalia and Fite ('74). The appearance of the neuropil was indicative of terminating tectal efferents. A small number of vesicle filled cells were also present in the contralateral lateral nucleus. Fibers from the contralateral area traveled across the posterior commissure and joined fibers from the ipsilateral nucleus. No neuropil was seen contralaterally.

Secondly, scattered HRP positive cells were seen in the ipsilateral anterodorsal, posterodorsal and posteroventral tegmental fields (fig. 4A). A marked concentration of cells afferent to the tectum was located dorsal to the interpeduncular nucleus near the midline. The projection from this suprapeduncular nucleus to the tectum is bilateral.

The ipsilateral nucleus isthmi was heavily labeled (figs. 1, 4B). The peripheral cells of the nucleus were densely filled with reaction product. Axons from these cells gathered in an isthmotectal tract and coursed to the tectum. A pale reaction also

Fig. 4 A Transverse section through the interpeduncular nucleus.

B Transverse section at the level of nucleus isthmi. Stippling in A and B marks the extent of the injection site.

C Transverse section through the medulla at the entrance of the eighth nerve. occurs in the neuropil core of the nucleus, and fibers from the tectum were traced into the core indicating a tectal efferent terminal field.

Evidence for retrograde transport of HRP was also seen in the cervical spinal cord (fig. 5). The cells of origin of this spinotectal projection are ipsilateral to the injected tectum, and are concentrated in the dorsal gray columns.

In half of the experimental animals, HRP positive cells were seen bilaterally in the ventral preoptic hypothalamus (fig. 2). We can only tentatively identify this as a site of tectal afferents since vesicle filled cells were not unequivocally seen in a majority of the animals.

In addition, large labeled cells were occasionally seen bilaterally in the medial and lateral reticular formations. However, the number and location of these reticular cells were too variable to definitely characterize this projection.

\section{Efferent pathways}

Both the ascending and descending tectal efferent tracts described by Rubinson ('68) were labeled. The ascending efferent bundle traveled from the injected tectum ventromedial to the ipsilateral optic tract (fig. 3A) turning medially to decussate in the postoptic decussation. After crossing, this bundle descended contralaterally in a position mirroring the ipsilateral component. The tract could be followed caudally to the contralateral rostral pretectum. 
Two descending components were also identified. The fibers of the crossed component exited the tectum, gathered in the ventrolateral tegmentum, and turned medially to decussate in the floor of the brain stem just rostral to the interpeduncular nucleus. This component took up a ventral paramedian position and turned caudally. A large portion of the second, ipsilateral, component intermingled with the isthmotectal fibers and terminated in nucleus isthmi. The remaining efferents coursed caudally in a ventrolateral position, more lateral than the corresponding crossed tract. A large number of ipsilateral fibers terminated in the superior olive (fig. 4C), staining the neuropil areas a pale brown. Occasional fibers from both components turned into the reticular formations. Neither tract could be traced with certainty caudal to the hypoglossal nucleus.

\section{DISCUSSION}

Both similarities and differences between this study and Trachtenberg and Ingle's ('74) are apparent. Their finding that the lateral nucleus is the primary source of pretectal afferents to the tectum, and that this projection is bilateral (but heavier ipsilaterally) is corroborated. Trachtenberg and Ingle could not distinguish a separate projection from the largecelled pretectal nucleus. Our data indicate that this latter nucleus also contributes a tectal input.

There are, however, some discrepancies. While Trachtenberg and Ingle concluded that the posterior nucleus did not innervate the tectum, scattered cells in the dorsal half of that nucleus were striking in their consistent appearance after tectal HRP injections. However, only a small portion of the posterior nuclear neurons were HRP positive. Partial lesions of the dorsal half of this cell group might have interrupted so few cells that demonstration of their axons was beyond the resolution of the degeneration techniques employed.

We could not confirm tectal afferents from the lateral geniculate found by
Trachtenberg and Ingle. Since this group is possibly homologous to the ventral lateral geniculate of mammals, a projection would be expected if the sparse projection in the cat (Edwards et al., '74) could be generalized to amphibians. It is possible that our negative finding results from this pathway being refractory to the HRP method. The question of rostral thalamic tectal inputs in amphibians is thus unsettled and awaits autoradiographic resolution.

We did not find a telencephalic input to the tectum, a result in agreement with earlier work on ranid frogs (Halpern, '72; Trachtenberg and Ingle, 74). This condition seems unique to anurans; a telencephalo-tectal projection exists in mammals (Nauta and Bucher, '54), birds (Karten, '69), reptiles (Butler and Ebbesson, '75), teleosts (Vanegas and Ebbesson, '76), and sharks (Ebbesson, 72). This absence in anurans is peculiar since the retina projects to thalamic areas (Scalia et al., '68; Neary, '76) and visual information is relayed to the telencephalon (Gruberg and Ambros, '74; Scalia and Colman, '75). Apparently forebrain visual areas do not influence the tectum directly, although a pretectal or tegmental relay may exist.

Neary (76) recently demonstrated ipsilateral retinotectals in several families of anurans. Our study did not reveal this pathway. However, in ranid frogs the ipsilateral input is primarily to the ventrolateral tectum. Since our injections did not extend there, the demonstration of this projection would not be expected.

Our results raise the possibility of tectal input from the preoptic hypothalamus. The area involved receives both retinal (Vullings and Kers, '73) and tectal (Rubinson, '68) input, although the degree of overlap is unclear. A hypothalamotectal projection has not been reported previously. Swanson (75, '76) investigated the preoptic area and suprachiasmatic nucleus in the rat and found three distinct preoptic fields projecting to the central gray beneath the superior colliculus, although none projected to the colliculus itself. It may be that 
the periventricular layers of the tectum in amphibians are homologous to mammalian central gray.

Amphibians, like reptiles (Foster and Hall, '75), possess reciprocal isthmo-tectal connections. The nucleus isthmi is also known to receive tectal efferents in fish (Ebbesson and Vanegas, "76; Sligar and Voneida, '76) and birds (Karten, '67). Whether the nucleus isthmi projects back to the tectum in those vertebrates remains to be demonstrated.

A projection from the suprapeduncular nucleus has not been previously described. Its position dorsal to the interpeduncular nucleus suggests it may be part of a monoamine system similar to that in mammals (Palkovits and Jacobowitz, '74). However, its characteristics and relationship to the nuclei of other vertebrates are unknown.

The orthograde HRP transport clearly reveals a heavy tectal input to the superior olive. This corroborates Rubinson's ('68) earlier findings. The superior olive in turn projects massively to the torus semicircularis (Rubinson and Skiles, '75). This circuit may be a way for visual input, or information on tectal output, to reach auditory integrating centers. Our results suggest that neither the torus nor the superior olive (as noted by Rubinson and Skiles, '75) feed back directly to the tectum. It is unclear whether auditory centers influence the tectum directly.

Our results suggest that an ipsilateral spinotectal projection is present in amphibians. This tract was suspected by early anatomists (Ariëns Kappers et al., '60), although recent experimental studies have not revealed it (Ebbesson, '69; Hayle, '73). Although the cells of origin are ipsilateral, it is likely that some of the primary afferents arise contralaterally. This direct spinotectal tract establishes one pathway by which somatosensory information reaches tectal units. It may not be the only route, since ascending spinal tracts do reach tegmental levels (Ebbesson, '69; Hayle, '73). Whether these tegmental areas relay somatosensory information to the tectum remains to be established.

The pretectal input's function is less clear than that of the spinal input. Our results narrow the choices of nuclei which could account for the disinhibition effect found after large caudal thalamic lesions (Ewert, '70). As Trachenberg and Ingle (74) stated, the lateral nucleus is a good candidate for the source of the effects. It accounts for the most massive tectal projection, it is in close association with direct retinal input via the uncinate neuropil, and it receives tectal feedback (Brown and Ingle, '73). In addition, these anatomical data agree well with Ewert's (et al., '74) behavioral results following restricted pretectal lesions. The significance of the other pretectal inputs is not known. The pretectum is involved in the amphibian's visual perception of barriers (Ingle, '73b) and in other vertebrates is implicated in oculomotor function (Graybiel, '74; Karten and Finger, '76). Although neither involves the tectum directly, the tectum may receive collateral information to appropriately modify reactions to moving objects.

These functional hypotheses are only speculative. The pretectum, a complex and functionally important area, is not well understood in any vertebrate. Our results, and those of Trachtenberg and Ingle ('74), show that only small portions of the pretectum innervate the tectum directly, and that two of these projections are minor. The connections and functions of the other cell populations await resolution.

\section{ACKNOWLEDGMENTS}

The authors wish to thank Doctor Timothy Neary who has also participated in HRP studies in this laboratory, and Doctor Mark Braford who provided thoughtful criticism of the manuscript. This work was supported by NIH 5 R01 NS11006 and NSF GB-40134.

\section{LITERATURE CITED}

Arien̈s Kappers, C. U., G. C. Huber and E. C. Crosby 1960 The Comparative Anatomy of the Nervous 
System of Vertebrates, Including Man. Hafner, New York.

Biesner, R., and R. Melzack 1966 Approach-avoidance responses to visual stimuli in frogs. Exp. Neur., 15: 418-424.

Broadwell, R. D., and M. W. Brightman 1976 Entry of peroxidase into neurons of central and peripheral nervous system from extracerebral and cerebral blood. J. Comp. Neur., 166: 257-284.

Brown, W. T., and D. Ingle 1973 Receptive field changes produced in frog thalamic units by lesions of the optic tectum. Brain Res., 59: 405-409.

Butenandt, E., and O.-J. Grüsser 1968 The effect of stimulus area on the response of movement detecting neurons in the frog's retina. Pfluegers Archiv., 298: 283-293.

Butler, A. B., and S. O. E. Ebbesson 1975 A Golgi study of the optic tectum of the tegu lizard, Tupinambis nigropunctatus. J. Morph., 146: 215-228.

Ebbesson, S. O. E. 1969 Brain stem afferents from the spinal cord in a sample of reptilian and amphibian species. Ann. N.Y. Acad. Sci., 167: 80-101.

1972 New insights into the organization of the shark brain. Comp. Biochem. Physiol., 42A: $121-129$.

Ebbesson, S. O. E., and H. Vanegas 1976 Projections of the optic tectum in two teleost species. J. Comp. Neur., 165: 161-180.

Edwards, S. B., A. C. Rosenquist and L. A. Palmer 1974 An autoradiographic study of the ventral lateral geniculate projections in the cat. Brain Res., 72 : 282-287.

Ewert, J.-P. 1970 Neural mechanisms of prey-catching and avoidance behavior in the toad (Bufo bufo, L), Brain, Behav. and Evol., 3: 36-56.

Ewert, J.-P., F. J. Hock and A. von Wietersheim 1974 Thalamus, Praetectum, Tectum: retinale Topographie und physiologische Interaktionen bei der Krote Bufo bufo (L.). J. Comp. Physiol., 92: 343356.

Foster, R. E., and W. C. Hall 1975 The connections and laminar organization of the optic tectum in a reptile (Iguana iguana) J. Comp. Neur., 16.3: 347 . 426.

Gaze, R. M. 1958 The representation of the retina on the optic lobe of the frog. Q. J. Exptl. Physiol., 43: 209-214.

Graybiel, A. M. 1974 Some efferents of the pretectal region in the cat. Anat. Rec., 178: 365.

Gruberg, E. R., and V. B. Ambros 1974 A forebrain visual projection in the frog (Rana pipiens). Exp. Neur., 44: 187-197.

Halpern, M. 1972 Some connections of the telencephalon of the frog, Rana pipiens. Brain, Behav. and Evol., 6: 42-68.

Hayle, T. H. 1973 A comparative study of spinal projections to the brain (except cerebellum) in three classes of poikilothermic vertebrates. J. Comp. Neur., 149: 463-476.

Ingle, D. 1968 Visual releasers of prey-catching behavior in frogs and toads. Brain, Behav. and Evol., 1: 500-518.
1970 Visuomotor functions of the frog optic tectum. Brain, Behav. Evol., 3: 57-71.

1971 Pre-catching behavior of anurans toward moving and stationary objects. Vision Res., Supplt. No. 3: 447-456.

1973a Disinhibition of tectal neurons by pretectal lesions in the frog. Science, 180: 422-424.

- $1973 \mathrm{~b}$ Two visual systems in the frog. Science, $181: 1053-1055$

Karten, H. J. 1967 The organization of the ascending auditory pathway in the pigeon (Columba livia). I. Diencephalic projections of the inferior colliculus (nucleus mesencephali lateralis, pars dorsalis). Brain Res., 6: 409-427.

1969 The organization of the avian telencephalon and some speculations on the phylogeny of the amniote telencephalon. Ann. N.Y. Acad. Sci., 167: $164-179$.

Karten, H. J., and T. E. Finger 1976 A direct thalamo-cerebellar pathway in pigeon and catfish. Brain Res., 102: 335-338.

Lazar, G. 1969 Efferent pathways of the optic tectum in the frog. Acta Biol. Acad. Sci. (Hungary), 20: 171-183.

1971 The projection of the retinal quadrants on the optic centres in the frog. Acta Morphologica Acad. Sci. (Hungary), 4: 325-344.

Lazar, G., and G. Szekely 1967 Golgi studies on the optic centers of the frog. J. Hirnforsch, 9: 329-344.

Lettvin, J. Y., H. R. Maturana, W. S. McCulloch and W. H. Pitts 1959 What the frog's eye tells the frog's brain. Proc. IRE, 47: 1940-1951.

Maturana, H. R., J. Y. Lettvin, W. S. McCulloch and W. H. Pitts 1960 Anatomy and physiology of vision in the frog (Rana pipiens). J. Gen. Physiol., 43:129175.

Nauta, W. H. J, and V. M. Bucher 1954 Efferent connections of the striate cortex in the albino rat. J. Comp. Neur., 100: 257-286.

Neary, T. J. 1975 Architectonics of the thalamus of the bullfrog (Rana catesbeiana): a histochemical analysis. Anat. Rec., 181: 434-435.

1976 An autoragiographic study of the retinal projections in some members of "archaic" and "advanced" anuran families. Anat. Rec., 184: 487.

Palkovits, M., and D. M. Jacobowitz 1974 Topographic atlas of catecholamine and acetylcholinesterase-containing neurons in the rat brain. II Hindbrain (mesencephalon, rhombencephalon). J. Comp. Neur., 157: 29-42.

Potter, H. D. 1969 Structural characteristics of cell and fiber populations in the optic tectum of the frog (Rana catesbeiana). J. Comp. Neur., 136: 203232.

Rubinson, K. 1968 Projections of the tectum opticum of the frog. Brain, Behav. and Evol., 1: 529561.

Rubinson, K, and M. P. Skiles 1975 Efferent projections of the superior olivary nucleus in the frog Rana catesbeiana. Brain, Behay. and Evol., 12: 151160.

Scalia, F., and D. R. Colman 1975 Identification of 
telencephalic-afferent thalamic nuclei associated with the visual system of the frog. Neursci. Abst., 1: 65.

Scalia, F, and K. Fite 1974 A retinotopic analysis of the central connections of the optic nerve in the frog. J. Comp. Neur., 158: 455-478.

Scalia, F., H. Knapp, M. Halpern and W. Riss 1968 New observations on the retinal projections in the frog. Brain, Behav. and Evol., 1: 324-353.

Sligar, C. M., and T. J. Voneida 1976 Tectal efferents in the blind cave fish Astyanax hubbsi. J. Comp. Neur., 165: 107-124.

Swanson, L. W. 1975 The efferent connections of the suprachiasmatic nucleus of the hypothalamus. J. Comp. Neur., 160: 1-12.

C 1976 An autoradiographic study of the efferent connections of the preoptic region in the rat. J. Comp. Neur., 167: 227-256.

Szekely, G. 1971 The mesencephalic and diencephalic optic centres in the frog. Vision Res. (Suppl.) 3: 269-279.

Trachtenberg, M. C., and D. Ingle 1974 Thalamotectal projections in the frog. Brain Res., 79: 419430.

Vanegas, H., and S. O. E. Ebbesson 1976 Telencephalic projections in two teleost species. J. Comp. Neur., 165: 181-196.

Vullings, H. G. B., and J. Kers 1973 The optic tracts of Rana temporaria and a possible retino-preoptic pathway. Z. Zellforsch., 139: 179-200.

Wilczynski, W. 1976 Some afferents to the ranid optic tectum: an HRP study. Anat. Rec., 184: 563. 